Jurnal Ekonomi Pembangunan Vol. 3, No. 2 (2017) 91-97

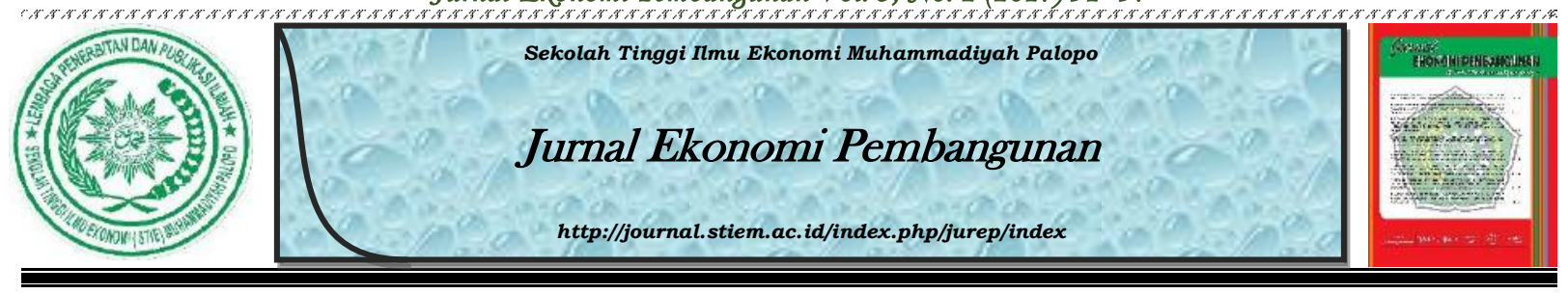

\title{
Peranan Pajak Hotel Terhadap Pertumbuhan Ekonomi Kota Palopo
}

Baharman Supri ${ }^{1}$, Rudianto $^{2}$

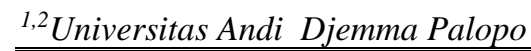

\section{INFO NASKAH}

(5)

Diserahkan

31 Oktober 2017

Diterima

2 November 2017

Diterima dalam revisi

18 Desember 2017

Diterima dan disetujui

18 Desember 2017

(18,9,5, D,

\section{Kata Kunci:}

Pajak hotel

Pertumbuhan

Ekonomi

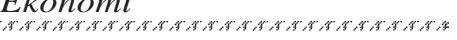

\begin{abstract}
ABSTRAK Era globalisasi dan pertumbuhan ekonomi yang begitu pesat membuat semua kalangan baik dari kalangan pemerintah maupun dari kalangan swasta harus berusaha untuk lebih mengutamakan kualitas dari pada kuantitas agar dapat memberikan hasil kerja yang maksimal. Agar dapat mencapai tujuan tersebut, seperti halnya dengan Kota Palopo ini yang merupakan Kota Niaga dan Kota Pendidikan tentunya pemerintah sangat berperan penting terutama pengaturan pajak khususnya pajak perhotelan atau pungutan atas pelayanan yang disediakan dengan pembayaran di hotel. Hotel di sini termasuk di dalamnya adalah rumah penginapan yang memungut pembayaran. Penelitian ini bertujuan untuk mengetahui seberapa besar peranan pajak hotel terhadap pertumbuhan ekonomi Kota Palopo. Hasil penelitian menunjukkan bahwa pertumbuhan ekonomi Kota Palopo selama lima tahun terakhir (2013-2017) masing-masing adalah $7,86 \% ; 7,82 \% ; 7,84 \% ; 7,90 \%$; dan 7,84\%. Sedangkan realisasi pajak hotel selama lima tahun terakhir (2013-2017) mengalami fluktuasi dengan nilai masing masing adalah $123,13 \% ; 105,51 \% ; 113,30 \%$; $121.21 \%$; dan $74.47 \%$.
\end{abstract}

\section{Pendahuluan}

Era globalisasi dan pertumbuhan ekonomi yang begitu pesat membuat semua kalangan baik dari kalangan pemerintah maupun dari kalangan swasta harus berusaha untuk lebih mengutamakan kualitas dari pada kuantitas. Hal ini dilakukan dalam rangka agar dapat memberikan hasil kerja yang maksimal dan dapat mencapai tujuan yang di harapkan. Seperti halnya dengan Kota Palopo yang merupakan Kota Niaga dan Kota Pendidikan tentunya pemerintah sangat berperan penting terutama pengaturan pajak khususnya pajak perhotelan atau pungutan atas pelayanan yang disediakan di hotel. Pengertian hotel di sini termasuk juga rumah penginapan.

\footnotetext{
Corresponding Author:

${ }^{1}$ baharmansupri@yahoo.com; +62 81355330448

2 rudianto.unanda@gmail.com; +62 81342237839
} 
Pertumbuhan ekonomi menekankan tinjauannya pada sejarah tahap-tahap pertumbuhan ekonomi serta ciri dan syarat masing-masing. Tahap-tahap tersebut adalah tahap masyarakat tradisional, tahap prasyarat lepas landas, tahap gerakan ke arah kedewasaan, dan tahap konsumsi tinggi negara berkembang dan faktor pertumbuhannya. Pertumbuhan ekonomi terjadi bila ada kenaikan output perkapita. Ekonomi menggambarkan kenaikan taraf hidup diukur dengan output ril per orang. Pertumbuhan ekonomi dan kenaikan sementara negaranegara miskin berpenduduk padat dan banyak hidup pada taraf batas hidup dan mengalami kesulitan menaikkannya. Beberapa negara seperti Amerika Serikat dan Kanada, negara-negara Eropa Barat, Australia, Selandia Baru, dan Jepang menikmati taraf hidup tinggi dan terus bertambah.

Pertambahan penduduk berarti pertambahan tenaga kerja serta berlakunya hukum pertambahan hasil yang mengakibatkan kenaikan output semakin kecil dan produk rata-rata serta penurunan taraf hidup. Sebaliknya kenaikan jumlah barang-barang kapital, kemajuan teknologi, serta kenaikan kualitas dan keterampilan tenaga kerja cenderung mengimbangi berlakunya hukum pertambahan hasil yang berkurang. Penyebab rendahnya pendapatan di negara-negara sedang berkembang adalah berlakunya hukum penambahan hasil yang semakin menurun akibat pertambahan penduduk sangat cepat.

Pembahasan mengenai pajak hotel didasarkan pada Undang-Undang Nomor 18 tahun 1997 tentang Pajak Daerah dan Nomor 32 tahun 2004 tentang Pemerintah Daerah yang menyatakan bahwa pemerintah dan DPRD menurut asas otonomi dan tugas pembantuan dengan prinsip otonomi yang seluas-luasnya dalam sistem dan prinsip NKRI sesuai dengan UUD RI tahun 1945 diberikan kewenangan mengurus dan mengatur semua urusan pemerintahan yang ditetapkan. Menurut UU ini, daerah memiliki kewenangan membuat kebijakan daerah untuk memberi pelayanan, peningkatan peran, prakarsa dan pemberdayaan masyarakat yang bertujuan pada peningkatan masyarakat yang merupakan bagian utama dari tujuan nasional.

Adanya peraturan tersebut, selama ini sudah dapat memberikan pengaruh positif terhadap peningkatan pendapatan daerah di Kota Palopo. Peningkatannya terjadi karena semakin diintensifkannya pemungutan dan bertambahnya jumlah objek pajak terutama pajak rumah makan, hotel dan lain-lain. Sebagaimana yang ditetapakan peraturan daerah Kota Palopo Nomor 27 tahun 2003 tentang Pajak Perhotelan, pemerintah daerah telah memanfaatkannya melalui perluasan kegiatan pembangunan setiap tahun walaupun belum secara optimal. 
Penelitian ini bertujuan untuk mengetahui seberapa besar peranan pajak hotel terhadap pertumbuhan ekonomi Kota Palopo.

\section{Metode Penelitian}

\subsection{Pendekatan Penelitian}

Data dalam penelitian ini diperoleh dengan metode observasi, interview, dan dokumentasi. Observasi dilakukan dengan mengamati secara langsung pada instansi terkait dalam hal ini adalah kantor Dinas Pendapatan Pengelolaan Keuangan dan Aset Daerah (DPPKAD) Kota Palopo. Interview dilakukan untuk mendapatkan informasi yang akurat dan lengkap tentang objek yang diteliti. Penulis menggunakan teknik interview dengan mengadakan wawancara atau tanya jawab langsung dengan pihak instansi yang berkaitan. Selain itu, penulis juga mengumpulkan data secara tertulis dari dokumen yang ada dan informasi lainnya yang berhubungan dengan penelitian ini.

\subsection{Analisis Data}

Metode analisis data yang digunakan dalam penelitian ini adalah analisis statistik yang akan dibahas melalui uji statistik, karena variabel dependen dipengaruhi oleh satu variabel bebas dan satu variabel terikat maka digunakan rumus regresi linier sederhana dengan persamaan sebagai berikut:

$\mathrm{Y}=\mathrm{a}+\mathrm{bX}+\mathrm{e}$

dimana $Y$ adalah pertumbuhan ekonomi; $a$ adalah konstanta; $X$ pajak hotel; $b$ adalah koefisien; dan $e$ adalah error term.

\section{Hasil dan Pembahasan}

Tingkat hunian hotel merupakan suatu keadaan sampai sejauh mana jumlah kamar terjual, jika diperbandingkan dengan seluruh jumlah kamar yang mampu untuk dijual. Oleh karena itu, industri pariwisata terutama kegiatan yang berkaitan dengan penginapan yaitu hotel, akan memperoleh pendapatan yang semakin banyak apabila wisatawan tersebut semakin lama menginap. Hotel di sini termasuk juga rumah penginapan yang memungut pembayaran. Hal ini berkaitan dengan kewenangan yang diberikan kepada pemerintah Kota Palopo tidak mengenakan suatu jenis pajak. 
Tabel 1. Target Pajak Hotel

\begin{tabular}{|c|r|r|r|}
\hline \multirow{2}{*}{ Tahun } & \multicolumn{1}{|c|}{$\begin{array}{c}\text { Target } \\
(\mathbf{R p})\end{array}$} & \multicolumn{1}{|c|}{ Perubahan } \\
\cline { 3 - 4 } & $125.224 .000,00$ & & \multicolumn{1}{c|}{ \% } \\
\hline 2013 & $4.738 .483 .750,00$ & $4.613 .259 .750,00$ & 97,35 \\
\hline 2014 & $130.224 .000,00$ & $-4.608 .259 .750,00$ & $-35,38$ \\
\hline 2015 & $7.415 .079,85$ & $-122.808 .920,15$ & $-16,56$ \\
\hline 2016 & $150.224 .000,00$ & $142.808 .920,15$ & 95,06 \\
\hline 2017 & $1.030 .314 .166,85$ & $6.250 .000,00$ & $-12,50$ \\
\hline Rata-Rata & & & \\
\hline
\end{tabular}

Sumber: Data diolah

Berdasarkan data pada tabel di atas, hasil menunjukkan bahwa target pajak hotel per tahun mengalami peningkatan yang berfluktuasi per tahunnya yaitu pada tahun 2013 sebesar Rp125.224.000; pada tahun 2014 sebesar Rp4.738.483.750; pada tahun 2015 sebesar Rp130.224.000; pada tahun 2016 sebesar Rp. 7.415.079,85; dan pada tahun 2017 sebesar Rp. 150.224.000 dengan rata-rata per tahun sebesar Rp1.030.314.166.

Bisnis hotel mempunyai tujuan mendapatkan keuntungan seoptimal mungkin melalui pemenuhan kebutuhan dan keinginan tamu (guest need and wants). Kepuasan tamu menjadi sasaran pelayanan untuk membentuk citra yang baik sekaligus menjamin keberadaan hotel dalam jangka panjang. Hotel yang berlokasi di daerah pinggiran kota besar yang jauh dari keramaian kota, tetapi mudah mencapai tempat-tempat kegiatan usaha. Hotel ini berlokasi di daerah-daerah tenang, terutama karena peruntukkan bagi masyarakat yang ingin tinggal dalam jangka waktu lama. Hotel ini dilengkapi dengan fasilitas tempat tinggal untuk seluruh anggota keluarga yang berlokasi di daerah pengunungan (mountain hotel) atau di tepi pantai (beach hotel), di tepi danau atau di tepi aliran sungai.

Berdasarkan hasil Pajak Hotel di Kota Palopo selama lima tahun terakhir (2013-2017) terlihat peningkatan yang cukup signifikan, begitupun dengan realisasinya yang terus mengalami peningkatan berfluktuasi. Sehingga rata-rata dapat mencapai peningkatan $100 \%$ per tahun. 
Tabel 2. Realisasi Pajak Hotel

\begin{tabular}{|c|r|r|r|}
\hline \multirow{2}{*}{ Tahun } & \multicolumn{1}{|c|}{$\begin{array}{c}\text { Realisasi } \\
\text { Pajak Hotel }\end{array}$} & \multicolumn{2}{|c|}{ Perubahan } \\
\cline { 3 - 4 } & $154.187 .182,00$ & & \% \\
\hline 2013 & $4.999 .701 .535,00$ & $4.845 .514 .353,00$ & - \\
\hline 2014 & $147.584 .738,00$ & $-4.852 .116 .797,00$ & $-36,92$ \\
\hline 2015 & $8.988 .020 .185,00$ & $8.840 .435 .447,00$ & 98,36 \\
\hline 2016 & $224.694 .230,00$ & $-8.763 .325 .955,00$ & $-39,00$ \\
\hline 2017 & $14.514 .187 .870,00$ & $70.507 .048,00$ & $-69,93$ \\
\hline Jumlah & $2.902 .837 .574,00$ & $17.626 .762,00$ & $-17,48$ \\
\hline Rata-Rata & & &
\end{tabular}

Sumber: Data diolah

Berdasarkan data pada tabel di atas, perhitungan menunjukkan bahwa target dan realisasi pajak hotel per tahun mengalami peningkatan yang berfluktuasi per tahunnya yaitu pada tahun 2013 sebesar Rp154.187.182, pada tahun 2014 sebesar Rp4.999.701.535, pada tahun 2015 sebesar Rp147.584.738, pada tahun 2016 sebesar Rp8.988.020.185, dan pada tahun 2017 sebesar Rp224.694.230, dengan rata-rata per tahun sebesar Rp. 2.902.837.574. Jika diamati Pertumbuhan Pajak Hotel di Kota Palopo selama lima tahun terakhir (2013-2017), terlihat peningkatan yang cukup signifikan, begitupun dengan realisasinya yang terus mengalami peningkatan sehingga rata-rata dapat mencapai $100 \%$.

Tabel 3. Target dan Realisasi Pajak Hotel

\begin{tabular}{|c|r|r|c|}
\hline Tahun & $\begin{array}{c}\text { Target } \\
(\mathbf{R p})\end{array}$ & $\begin{array}{c}\text { Realisasi } \\
(\mathbf{R p})\end{array}$ & $\begin{array}{c}\text { Persentase } \\
(\boldsymbol{\%})\end{array}$ \\
\hline 2013 & $125.224 .000,00$ & $154.187 .182,00$ & 123,13 \\
\hline 2014 & $4.738 .483 .750,00$ & $4.999 .701 .535,00$ & 105,51 \\
\hline 2015 & $130.224 .000,00$ & $147.584 .738,00$ & 113,30 \\
\hline 2016 & $7.415 .079,85$ & $8.988 .020 .189,00$ & 121,21 \\
\hline 2017 & 150.224 .000 .00 & $224.694 .230,00$ & 74,47 \\
\hline
\end{tabular}

Sumber: DPPKAD Kota Palopo

Berdasarkan tabel di atas, data menunjukkan bahwa target dan realisasi pajak hotel selama lima tahun terakhir (2013-2017) mengalami peningkatan yang berfluktuasi yaitu pada tahun 2013 target sebesar Rp125.224.000 sedangkan realisasinya menjadi Rp154.187.182 dengan persentase 123,13; pada tahun 2014 target sebesar Rp4.738.483.750 sedangkan realisasinya hanya sebesar Rp4.999.701.535 dengan persentase sebesar 105,51; pada tahun 2015 target pajak hotel sebesar Rp130.224.000 sedangkan realisasinya meningkat menjadi Rp147.584.738 dengan persentase sebesar 113,30; pada tahun 2016 target pajak hotel sebesar Rp7.415.079,85 dan realisasinya meningkat sebesar Rp8.988.020.185 dengan persentase sebesar 121,21; dan pada tahun 2017 target sebesar Rp150.224.000 sedangkan realisasinya 
turun menjadi Rp224.694.230 dengan persentase sebesar 74.47.

Tabel 4. Pertumbuhan Ekonomi

\begin{tabular}{|c|r|r|r|}
\hline Tahun & $\begin{array}{c}\text { Nilai Pertumbuhan } \\
(\mathbf{R})\end{array}$ & $\begin{array}{c}\text { Realisasi } \\
(\mathbf{R p})\end{array}$ & $\begin{array}{c}\text { Persentase Pertumbuhan } \\
(\boldsymbol{\%})\end{array}$ \\
\hline 2012 & $10.971 .800,77$ & - & 7,86 \\
\hline 2013 & $11.833 .993,00$ & $962.192,23$ & 7,82 \\
\hline 2014 & $12.759 .075,15$ & $1.000 .569,31$ & 7,84 \\
\hline 2015 & $13.759 .644,46$ & $1.087 .419,80$ & 7,90 \\
\hline 2016 & $14.847 .064,26$ & $1.163 .862,23$ & 7,84 \\
\hline 2017 & $16.010 .926,49$ & & \\
\hline
\end{tabular}

Sumber: Data per Oktober 2017

Pertumbuhan ekonomi Kota Palopo selama lima tahun terakhir (2013-2017) masingmasing adalah 7,86\%;7,82\%;7,84\%; 7,90\%; dan 7,84\%. Sedangkan realisasi pajak hotel selama lima tahun terakhir (2013-2017) mengalami fluktuasi dengan nilai masing masing adalah $123,13 \% ; 105,51 \% ; 113,30 \% ; 121.21 \%$; dan $74.47 \%$.

\section{Simpulan dan Saran}

Berdasarkan uraian sebelumnya dalam penelitian ini, kesimpulan dari penelitian yang bertujuan untuk mengetahui seberapa besar peranan pajak hotel terhadap pertumbuhan ekonomi Kota Palopo ini adalah pertumbuhan ekonomi Kota Palopo selama lima tahun terakhir (2013-2017) masing-masing adalah 7,86\%; 7,29\%; 8,16\%; 8,68\%; dan 9,26\%. Sedangkan realisasi pajak hotel selama lima tahun terakhir (2013-2017) mengalami fluktuasi dengan nilai masing masing adalah $123,13 \%$; 105,51\%; 113,30\%; $121.21 \%$; dan $74.47 \%$.

Pemerintah Kota Palopo khususnya Dinas Pendapatan dan Pengelolaan Keuangan Aset Daerah (DPPKAD) dalam menetapkan target pajak hotel di masa yang mendatang diharapkan berpatokan pada potensi ril yang ada pada setiap obyek hotel melalui peremajaan data tentang jumlah obyek pajak hotel yang ada di Kota Palopo. Selain itu, perlu menerapkan sistem berbasis potensi dalam penetapan pembayaran pajak hotel; merancang komputerlisasi (on line) dalam penerapan pengelolaan pajak hotel; memberikan pemahaman kepada setiap wajib pajak melalui berbagai metode, seperti meningkatkan wawasan tentang pajak hotel; dan menggelar even-even yang bisa menarik wisatawan baik lokal maupun asing.

\section{Daftar Pustaka}

Andi, P. dan K. Bambang. 2006. Hukum Pajak. Yogyakarta: Ekonesia. 
Anonim. 1995. Undang-Undang Perpajakan. Bandung: Citra Umbara.

Baridwan, Z. 2008. Intermediate Accounting. Edisi Kedelapan. Yogyakarta: BPFE YKPN.

Djojohadikusomo, S. 2000. Indonesia dalam Pembangunan Dunia Kini dan Masa Datang. Jakarta: LP3ES.

Lincolin, A. 2005. Ekonomi Pembangunan. Edisi Keempat. Yogyakarta: STIE YKPN.

Mangkoesoebroto. 2005. Ekonomi Publik. Edisi Pertama. Yogyakarta: Liberty.

Mardiasmo.1992. Perpajakan. Edisi Revisi. Yogyakarta.

Mardiasmo. 2003. Perpajakan. Edisi Revisi. Yogyakarta.

Munawir. 1998. Perpajakan. Yogyakarta: Andi.

Republik Indonesia. Peraturan Menteri Keuangan Nomor 29 Tahun 2005 tentang Tata Cara Pembayaran Kembali Kelebihan Pembayaran Pajak Bumi dan Bangunan.

Republik Indonesia. Undang-Undang Nomor 28 Tahun 2009 tentang Pajak Daerah dan Retribusi Daerah.

Republik Indonesia. Undang-Undang Nomor 12 Tahun 1985 Tentang Pajak Bumi dan Bangunan telah dikeluarkan beberapa Peraturan Pemerintah, SK Menteri Keuangan dan SK Direktur Jenderal Pajak.

Risma. 2004. Perpajakan. Bandung: PT Eresco.

Siagian. 2005. Perpajakan. Edisi Revisi. Yogyakarta.

Soemarso. 2008. Akuntansi Suatu Pengantar. Edisi Kelima. Jakarta: Salemba Empat.

Soemitro, H. R. 1989. Pajak Bumi dan Bangunan. Bandung: PT Eresco.

Soeparmoko. 1998. Pajak. Edisi Revisi. Yogyakarta.

Sugiyono. 2015. Metode Penelitian Bisnis. Bandung: Alfabeta.

Wahab, S. 2007. Kebijaksanaan Sektor Pariwisata. Yogyakarta: Andi Offset.

Waluyo. 2008. De Economische Betekenis Belastingen. Yogyakarta: Ekonesia. 